\title{
Ueber die Bildung kolloider Lösungen mittelst Flammen oder elektrischer Entladungsfunken.
}

\author{
Von Julius Donau (Graz).
}

(Lingegangen atw 26. März 1915.)

Als ich mich vor einiger Zeit mit der Untersuchung von Lumineszenzerscheinungen von Erdalkalisalzen in der Wasserstofflamme befaBte $^{1}$ ), beobachtete ich bei der Behandlung einer sehr verdünnten Goldlösung mit einer Wasserstofflamme die Bildung roten kolloiden Goldes. Auf gleiche Weise färbten sich Lösungen von $\mathrm{Silbernitrat}$ gelb bis braungelb, $\mathrm{Pall}$ adium chlorürlösungen $\mathrm{schwar} z$, Platinsalzlösungen rehbraun. Eine Lösung von molybdä n saurem Ammon wurde alsbald dunkelbla u. Daß die genannten Färbungen auf die Entstehung kolloider Lösungen zurückzuführen sind, beweisen alle in dieser Richtung angestellten Versuche.

Ueber die Ursache dieser Erscheinung sprach ich mich 1. c. nicht genauer aus, sondern stellte nur die Mutmaßung auf, daß der Wasserstoffflamme eine besondere Reduktionswirkung zukomme. Mittlerweile haben sich auch $W$. $\mathrm{Halle}$ und E. P r i b $\mathrm{ram}^{2}$ ) gelegentlich einer Untersuchung über den Einfluß der Elektrolytkonzentration auf die Teilchengröße mit der Sache beschäftigt und gefunden, daß die Entstehung der roten Goldlösung nicht allein auf der Reduktionswirkung der Wasserstofflamme beruht, sondern vielmehr auf das Auftreten von salpetriger Säure in der mit der Flamme behandelten Lösung zurückzuführen ist. Die genannten Forscher weisen in dieser Lösung die salpetrige Säure mittelst Sulfanilsäure- $\alpha-$ Naphthylamin in der Tat nach und es gelang ihnen ebenso, verdünnte Lösungen von Goldchlorid durch verdünnte Lösungen von salpetriger Säure kolloid zu reduzieren. Die dabei erhaltenen Lösungen waren je nach der Konzentration der angewandten Lösungen blau, violett oder rot. - Mehrere in dieser Richtung gemachten Versuche bestätigten diese Ansicht vollauf. Nur muß ich bemerken, daß es mir allerdings nicht gelang, eine kolloide Goldlösung zu erhalten, wenn ich einem mit der Wasserstofflamme vorbehandelten Wasser, das Jod aus Jodiden frei machte und die Reaktion auf salpetrige Säure zeigte, erst nach-

1) J. Don a u, Monatsh. f. Chemie 34, 335-341 ; vgl. auch das Referat in diesem Heft der „, KolloidZeitschrift".

2) W. Halle und E, Pribram, Ber, d. Deutsch, chem. Ges. 47, 1398. trägli ch verdünnte Goldlösung zusetzte. Anfangs trat keine sichtbare Färbung oder Fällung ein; erst nach mehreren Stunden war eine Reduktionswirkung $\mathrm{zu}$ benterken, indem sich metallisches Gold am Boden des Gefäßes ansetzte. W. Halle und E. Př ibram erwähnen nicht, diesen Versuch gemacht zu haben, erhielten aber, wie oben gesagt, beim Vermischen verdünnter Lösungen von Goldchlorid und salpetriger Säure neben blauen und violetten auch rote Goldsole. Wahrscheinlich spielt bei der Flammenwirkung die Elektrolytkonzentration eine wesentliche Rolle, oder es handelt sich um eine örtliche Wirkung der vom Wasser absorbierten Stickoxyde. Wenn nun mit der Bildung salpetriger Säure die Entstehung kolloider Lösung zusammenhängt, so müßten auch andere Flammen und Mittel, durch welche salpetrige Säure erzeugt wird, die gleiche Wirkung haben. W. Halle und E. Pr̈ibram haben dies auch bei der Kohlenoxyd-, Methan- und Leuchtgasflamme mit Erfolg versucht. Ich habe noch den gleichen Versuch mit der einfachen und mit der Knallgasgebläseflamme gemacht und ebenfalls Reduktion unter Bildung kolloider Lösungen beobachtet. Da jedoch durch diese beiden Flammen verhältnismäßig viel mehr Stichoxyde entstehen, trat wegen der höheren Elektrolytkonzentration meistens eine violette oder blaue, seltener rote Farbe auf. Die letztere erhält man stets, wenn man der Lösung vorher etwas von einem Schutzkolloid hinzufügt. Ein schöner Beweis für die Richtigkeit der Halle und Pribram'schen Ansicht ist die Wirkung des Induktionsfunkens. Wenn man nämlich einen solchen längere Zeit in eine sehr verdünnte Goldchloridlösung überspringen läßt, so entsteht gleichfalls eine rote kolloide Goldlösung. Ich habe den Versuch so angestellt, daß die Induktionsstromleitungsdrähte (mit Platindrahtenden) in ein Becherglas bis nahe an die Oberfläche der darin befindlichen verdünnten Goldlösung hingen. Durch ein mehrere Minuten andauerndes Ueberspringenlassen des Funkens in die Lösung entsteht eine immer deutlichere Rotfärbung der Flüssigkeit. Diese Reduktionswirkung können allem Anschein nach nur die bei der elektrischen Entladung gebildeten und vom Wasser aufgenommenen Stickoxyde verursacht haben. 